\title{
Anomalous Origin of the Right Coronary Artery from the Mid-Portion of the Left Anterior Descending Artery in a Patient with Single Left Coronary Artery: A Rare Coronary Artery Anomaly and Review of
}

\section{Literature}

\author{
Mahmoud Beheshti Monfared, ${ }^{1}$ Hamid Ghaderi, ${ }^{1}$ Taraneh Faghihi Langroudi, ${ }^{2}$ Seyedeh Adeleh \\ Mirjafari, ${ }^{3,}{ }^{*}$ Mahnoosh Foroughi, ${ }^{4}$ Mohammad Forozeshfard, ${ }^{5}$ and Farshid Heidarpour Kiaie ${ }^{6}$ \\ ${ }^{1}$ Department of Cardiovascular Surgery, Shahid Modarres Hospital, Shahid Beheshti University of Medical Sciences, Tehran, Iran \\ ${ }^{2}$ Department of Radiology, Shahid Modarres Hospital, Shahid Beheshti University of Medical Sciences, Tehran, Iran \\ ${ }^{3}$ Brain and Spinal Injury Research Center (BASIR), Tehran University of Medical Sciences, Tehran, Iran \\ ${ }^{4}$ Cardiovascular Research Center, Department of Cardiovascular Surgery, Shahid Modarres Hospital, Shahid Beheshti University of Medical Sciences, Tehran, Iran \\ ${ }^{5}$ Departmant of Anesthesiology, Semnan University of Medical Sciences, Semnan, Iran \\ ${ }^{6}$ Cardiovascular Research Center, Department of Cardiology, Shahid Modarres Hospital, Shahid Beheshti University of Medical Sciences, Tehran, Iran \\ "Corresponding author: Seyedeh Adeleh Mirjafari, Brain and Spinal Injury Research Center (BASIR), Imam Khomeini Hospital Complex, Keshavarz Blvd., Tehran, Iran. Tel: \\ +98-2166581561, E-mail: adeleh_60@yahoo.com
}

Received 2014 September 09; Revised 2014 October 26; Accepted 2014 November 15.

\begin{abstract}
Origination of the right coronary artery (RCA) from the left anterior descending (LAD) artery is a case of single coronary artery. It is an extremely rare coronary artery abnormality and usually an incidental finding during coronary angiography. A 73-year-old man with a medical history of hypertension arrived with chest pain. Medical therapy started for ST elevated myocardial ischemia. During his diagnostic coronary angiogram, RCA was visualized as abnormally orientating from the mid-portion of LAD. A significant lesion in the proximal part of LAD, significant long lesion in the diagonal artery, and several stenoses in the obtuse marginal artery (OMA) were observed. To evaluate the course of RCA, coronary computed tomography angiography (coronary CTA) scan was performed. The patient underwent coronary artery bypass graft (CABG) for three vessels. He was discharged without any complication and no problems were detected in follow-up. In conclusion, if during classic angiography, RCA is not seen, the physician should keep in mind that RCA may originate from LAD. Current classification cannot exactly determine this anomaly and needs revision. When there is suspicion for coronary anomaly, performing coronary CTA can be helpful for better management and planning of therapy.
\end{abstract}

Keywords: Anomalous Coronary Artery, Right Coronary Artery, Left Anterior Descending Artery, Diagnosis, Therapy

\section{Introduction}

The term "single coronary artery" emphasizes on a coronary artery originating from a single coronary ostium on the aorta. Origination of the right coronary artery (RCA) from the left anterior descending (LAD) artery is a type of single coronary artery that is an extremely rare coronary artery abnormality (incidence $0.024 \%$ ) (1). It is usually an incidental finding during coronary angiography (2).

We found only less than 40 case reports in which RCA originated from LAD and just less than 15 case reports in which RCA originated from the mid-portion of LAD in PubMed. In most of the published cases, anomalous RCA originated from the left main artery (LMA) or proximal portion of LAD (3).

We present a patient with multiple stenoses in the proximal part of LAD, long lesion in the diagonal artery, several stenoses in the obtuse marginal artery (OMA), and
RCA arose from the mid-portion of LAD.

\section{Case Presentation}

A 73-year-old man was admitted to our hospital complaining of chest pain and functional class III-IV. His medical history consisted of hypertension. He was a smoker and had suffered from chest pain for 2 weeks. On admission, his electrocardiogram (ECG) showed ST segment elevation in leads I, II, aVL and V3-V6 associated with right anterior hemiblock. Cardiac enzyme levels were elevated. His transthoracic echocardiogram was normal. Medical therapy was started for ST elevated myocardial ischemia and diagnostic coronary angiogram was performed. During his diagnostic coronary angiogram, multiple attempts for cannulation of the RCA by right Judkins catheter were unsuccessful and the catheter could not be engaged in the ostium of the RCA. Aortic root angiography showed no def- 
inite origin for RCA on the right sinus of Valsalva. The left coronary ostium was located normally and its cannulation was performed displaying a normal course of LAD and showed dominance of left circumflex (LCX) (Figures 1 and 2). RCA was visualized originating anomalously from the mid-portion of LAD. A significant lesion in the proximal part of LAD, significant long lesion in the diagonal artery and several stenoses in OMA were observed. Left ventriculography was normal, with an ejection fraction of $55 \%$. Neither aortography nor pulmonary artery angiography showed presence of another origin for a supplementary RCA.

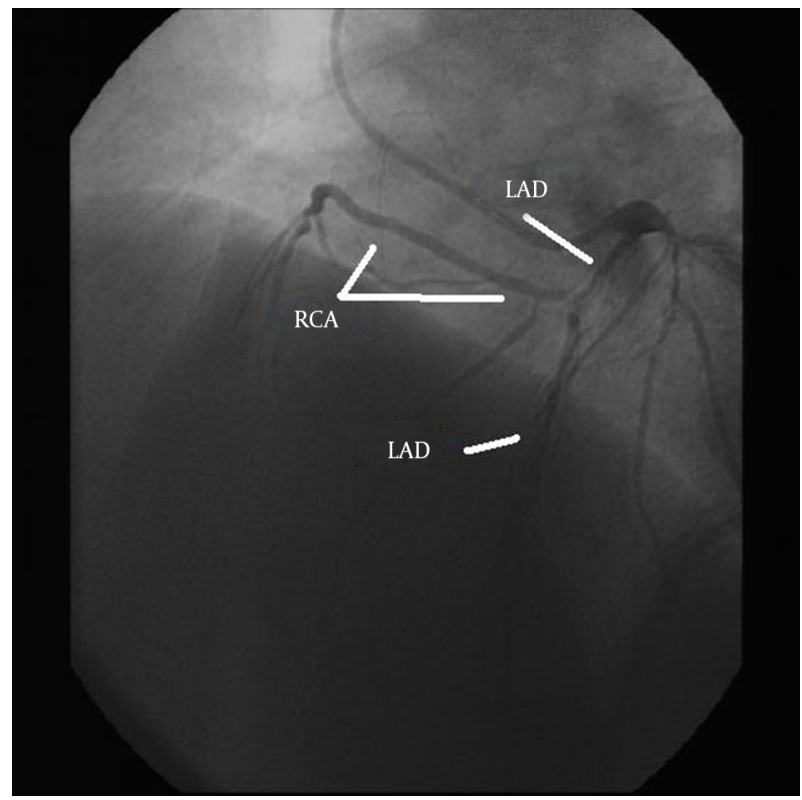

Figure 1. A 73-year-old man with chest pain who underwent angiography. Right coronary artery originating from the mid-portion of the left anterior descending artery. LAD, left anterior descending; RCA, Right Coronary Artery.

To evaluate the course of RCA (posterior or anterior to the pulmonary artery) and to exclude the presence of any origin for a supplementary RCA from another site, coronary CTA was performed using 64-slice single-source scanner (Brilliance 64, Philips Medical System, Cleveland, $\mathrm{OH}$, USA) (Figures 3 and 4). The coronary CTA showed the origin of RCA on the mid-portion of LAD passing horizontally anterior to the pulmonary artery and entering the right atrioventricular groove.

The patient was referred for coronary artery bypass graft (CABG) and he was evaluated by cardiovascular surgeons for surgical treatment. The patient underwent coronary artery bypass graft and the findings during surgery confirmed the findings of angiography and coronary CTA (Figure 5). He underwent coronary artery bypass graft-

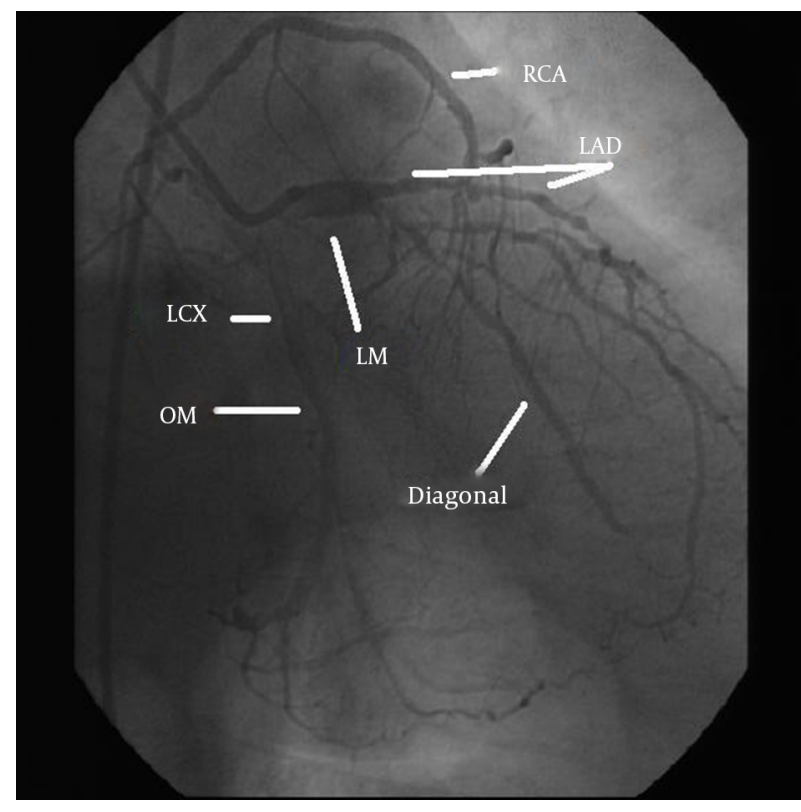

Figure 2. Right coronary artery originating from the mid portion of the left anterior descending Artery. LM, left main; LAD, left anterior descending; OM, obtuse marginal; LCX, left circumflex artery; RCA, right coronary artery.

ing (CABG) for three vessels; left internal mammary artery (LIMA) to LAD, and three saphenous vein grafts to RCA and diagonal and OMA. He was discharged 8 days after surgery with no complication. His echocardiogram on follow-up showed good biventricular function.

\section{Discussion}

Coronary artery anomaly exists in $0.6 \%$ to $5.6 \%$ of patients undergoing coronary angiography, $1 \%$ of routine autopsy studies $(3,4)$, and $2.93 \%$ of coronary CT angiographies (5).

The most common coronary anomaly is the circumflex coronary artery arising from the right sinus or from RCA $(0.37 \%-0.6 \%)(2,5)$, right coronary artery arising from the left sinus of Valsalva and the left main coronary artery arising abnormally from the right sinus of Valsalva $(0.17 \%$ in autopsy series and $0.1 \%-0.3 \%$ in patients undergoing catheterization or echocardiography) $(2,6,7)$.

Lipton reported single coronary artery in approximately $0.024 \%$ of the general population (1). A variety of anomalous origins of RCA(left anterior sinus with variable courses, ascending aorta above the sinus level, descending thoracic aorta, left main coronary artery, circumflex coronary artery, the pulmonary arteries, or below the aortic valve) have been reported $(8,9)$. 

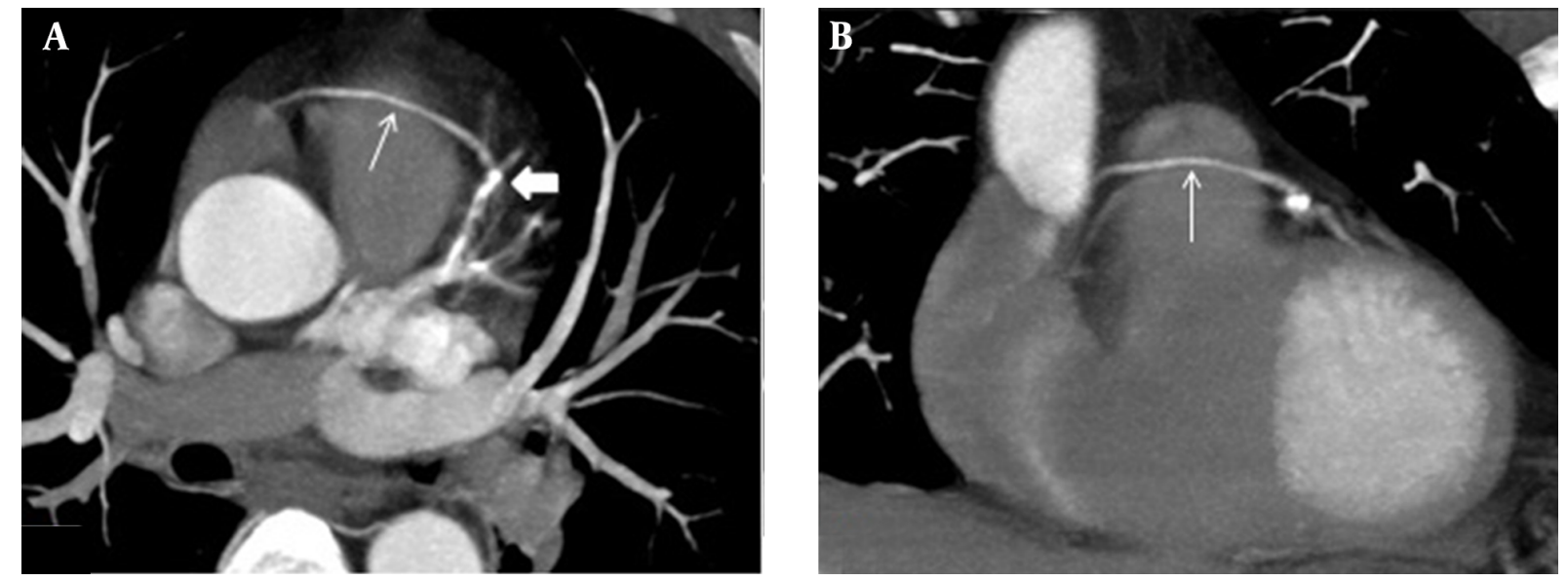

Figure 3. Maximum intensity projection in axial (A) and coronal (B) planes of coronary computed tomography angiography. The right coronary artery (thin arrow) originates from the midportion of the left anterior descending (thick arrow) passing anterior to the pulmonary artery.

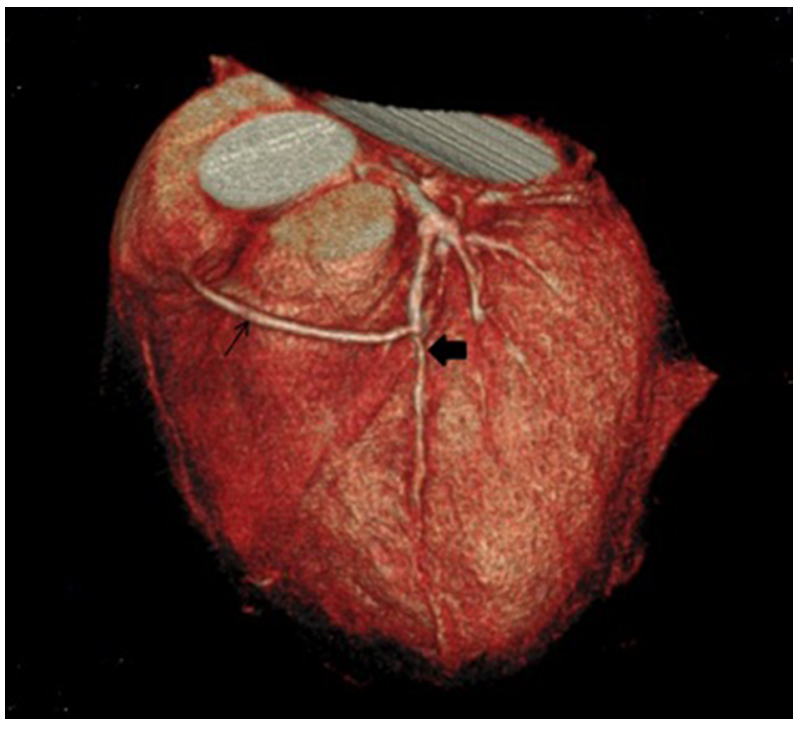

Figure 4. Three-dimensional volume-rendered reconstruction of coronary computed tomography angiography angiogram. Right coronary artery (thin arrow) originates from the midportion of the left anterior descending (thick arrow) passing anterior to the pulmonary artery.

Anomalous origin of RCA (ARCA) from LAD has rarely been reported and we found only less than 40 published cases with this specific coronary anomaly (10). In the most of these reported cases, ARCA originated from $\operatorname{LM}(2,7)$. There was only 15 reported cases in which the origin of ARCA was from the midportion of $\operatorname{LAD}(2,3)$ (Table 1 ).

According to modified Lipton classification, our case can be categorized as "LIIA" anomaly (23). (L type: single coronary artery arising from the left sinus of Valsalva; group II: arise from the proximal part of the normal right or left coronary artery; A (anterior): anomalous coronary artery passes anterior to the pulmonary artery) $(3,23)$. However, this classification can not exactly define a coronary artery anomaly that originates from the midportion of LAD.

Although single coronary artery is commonly associated with other congenital cardiovascular anomalies such as transposition of the great vessels, coronary arteriovenous fistula, bicuspid aortic valve, tetralogy of Fallot and origin from the pulmonary artery (3), most of the patients (97\%) with RCA arising from LAD have a structurally normal heart (9). Only two of the cases had association with tetralogy of Fallot $(24,25)$.

Prognosis of this type of anomaly on depends on the coronary perfusion. The anomalous vessel with the interarterial course (between aorta and pulmonary arteries) is considered malignant or serious and the prognosis is better for a vessel with an anterior course .If the course of RCA is not between the aorta and pulmonary artery, this anomaly has a better prognosis (2). Benign anomalous addresses an anomalous in which the LCX originates from the right circulation $(26,27)$ and we will not discuss this anomaly in this article.

If ARCA is compressed between the pulmonary artery and aorta, myocardial ischemia and sudden death may occur $(3,28)$. Some studies suggest that ARCA is prone to atherosclerosis (22) but in 15\% of patients with ARCA, myocardial ischemia can progress without atherosclerosis (3).

Some hypotheses explain myocardial ischemia and sudden death due to coronary vasospasm, acute angle take off, slit like orifice, intramural course, and compression by the great vessels (3). Some studies based on autopsy 

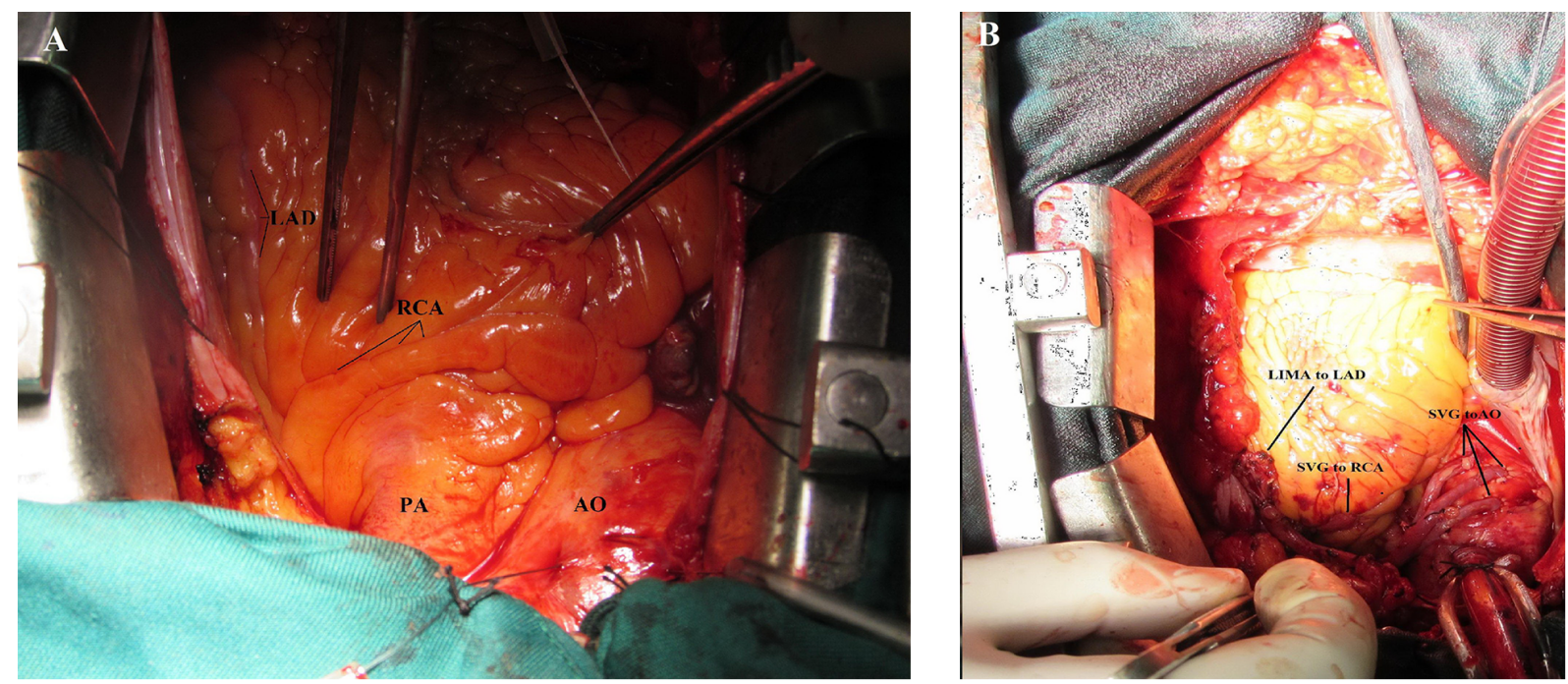

Figure 5. The course of the right coronary artery. A, Intraoperative photo; B, After coronary artery bypass graft (CABG). LAD, left anterior descending; RCA, right coronary artery; AO, aorta; PA, pulmonary artery; LIMA to LAD, anastomosis of left internal mammary artery to left anterior descending artery; SVG to AO, anastomosis of saphenous vein grafts to aorta; SVG to RCA, anastomosis of saphenous vein grafts to right coronary artery.

cases have shown that slit-like orifice structure and acute angle take off are more common in sudden cardiac death patients $(2,25,29)$.

Patients with ARCA may be asymptomatic and 25\% of them die suddenly (29). Patients with coronary anomaly may present with chest pain, dyspnea, palpitation, syncope, sudden death, ventricular fibrillation or myocardial infarction (3). Our patient presented with myocardial infarction.

A diagnostic tool for ARCA is coronary angiography and they are usually an incidental finding. If RCA is not seen during classic angiography, the physician should keep in mind that RCA can originate from LAD. Coronary CTA is a very useful diagnostic tool to determine the anatomy of the coronary arteries, the possible anomalies, and their relationship with great vessels (30). CT angiography is the gold standard investigation tool in evaluating coronary anomalies and their anatomic relationship to adjacent structures $(3,30)$. Recent guidelines and appropriateness criteria favor the use of coronary CTA for the evaluation of coronary anomalies (31).

Treatments for coronary anomaly include medical therapy, percutaneous coronary intervention (PCI), and surgery. Medical treatment is useful when the patient is asymptomatic and ARCA is not malignant or in other words is not compressed between the aorta and pulmonary artery (3). Although some studies reported PCI for anomalous RCA arising from LAD, but PCI is not wildly used because of single coronary orifice and different anatomical structures in these patients (3). Cardiac surgery is very important in these patients. Recommended surgical therapies in this anomaly include ostioplasty, bypass graft of the RCA, reimplantation of RCA to the aorta, and pulmonary artery translocation $(2,3)$. However, the long-term outcome of such therapies is not confirmed.

In conclusion, when RCA is not seen during classic angiography, the physician should keep in mind that RCA can originate from LAD. Anomalous RCA usually stems from proximal or mid-portion of LAD. Current classification cannot exactly determine this anomaly and it needs to be revised. When there is suspicion for coronary anomaly, then performing coronary CTA for better management and planning of therapy can be helpful.

\section{Acknowledgments}

None declared.

\section{Footnote}

Authors' Contributions: All authors contributed extensively to the work presented in this paper. Seyedeh Adeleh Mirjafari was the corresponding author and helped in all aspects. Mahmoud Beheshti Monfared and Hamid Ghaderi were the cardiac surgeons. Mohammad Forozeshfard was the anesthesiologist. Taraneh Faghihi Langroudi contributed to the radiologic findings. Farshid Heidarpour Kiaie was the technical and material support. Seyedeh Adeleh Mirjafari and Mahnoosh Foroughi prepared the 
Table 1. Overview of Published Reports Regarding Patients with Anomalous Origin of the Right Coronary Artery from the Mid-Portion of the Left Anterior Descending Artery

\begin{tabular}{|c|c|c|c|c|c|c|c|c|}
\hline Author/Referrence & Publish Year & Age & Sex & Symptom & ECG & Course of RCA & CAD & Treatment \\
\hline Nath et al. (11) & 1987 & 65 & M & Exertional angina & Normal & Anterior to PA & No & Unknown \\
\hline Nath et al. (11) & 1987 & 54 & M & Exertional angina & $\begin{array}{l}\text { Precordial ST } \\
\text { depression }\end{array}$ & Anterior to PA & $\begin{array}{c}\text { Proximal LAD 75\%, } \\
\text { RCA } 80 \%\end{array}$ & Unknown \\
\hline Biffani et al. (12) & 1991 & 54 & $\mathrm{~F}$ & Angina at rest & $\begin{array}{l}\text { Precordial ST } \\
\text { depression }\end{array}$ & Anterior to PA & No & Unknown \\
\hline $\begin{array}{l}\text { Rath and Battler } \\
\text { (13) }\end{array}$ & 1998 & 77 & M & Exertional fatigue & Normal & Anterior to PA & $\begin{array}{l}\text { Non-critical } \\
\text { stenosis }\end{array}$ & Medical \\
\hline Iyisoy et al. (14) & 2002 & 53 & M & Angina at rest & Normal & Posterior to PA & No & Unknown \\
\hline Takano et al. (15) & 2003 & 35 & M & Angina & ST-T wave changes & Anterior to PA & Severe LAD stenosis & PCI \\
\hline $\begin{array}{l}\text { Jammula et al. } \\
(16)\end{array}$ & 2005 & 45 & $\mathrm{~F}$ & Exertional angina & Normal & Not available & $\begin{array}{l}\text { Non-critical } \\
\text { stenosis }\end{array}$ & Medical \\
\hline $\begin{array}{l}\text { Saravanan et al. } \\
\text { (17) }\end{array}$ & 2006 & 59 & $\mathrm{~F}$ & Atypical angina & Normal & Anterior to PA & No & Medical \\
\hline $\begin{array}{l}\text { Kamran and } \\
\text { Bogal (18) }\end{array}$ & 2006 & 39 & M & Endocarditis & Normal & Anterior to PA & No & Medical \\
\hline Erdogan et al. (19) & 2008 & 44 & $\mathrm{~F}$ & Angina & Normal & Anterior to PA & $\begin{array}{c}\text { Stenosis in } \\
\text { circumflex artery }\end{array}$ & Medical \\
\hline Bayram et al. (20) & 2008 & 51 & M & Angina & Normal & Anterior to PA & Normal & Medical \\
\hline Hsueh et al. (21) & 2009 & 72 & F & Angina & ST-T wave change & Not available & 95\% LAD stenosis & $\mathrm{PCI}$ \\
\hline Calabro et al. (22) & 2009 & 53 & $\mathrm{~F}$ & Angina & Normal & Not available & LAD stenosis & $\mathrm{PCI}$ \\
\hline $\begin{array}{l}\text { Tokmakoglu et al. } \\
\text { (2) }\end{array}$ & 2010 & 66 & M & $\begin{array}{l}\text { Exertional chest } \\
\text { pain }\end{array}$ & Normal & Anterior to PA & $\begin{array}{l}\text { Severe stenosis on } \\
\text { ostium of } \\
\text { anomalous RCA, } \\
\text { mid portion of LAD } \\
\text { and circumflex }\end{array}$ & $\begin{array}{l}\text { CABG for three } \\
\text { vessel disease }\end{array}$ \\
\hline $\begin{array}{l}\text { Yurtdas and } \\
\text { Gulen (3) }\end{array}$ & 2012 & 65 & M & Chest pain & Normal & Anterior to PA & $\begin{array}{l}\text { Non-critical } \\
\text { stenosis }\end{array}$ & Medical \\
\hline $\begin{array}{l}\text { Beheshti } \\
\text { Monfared et al. } \\
\text { (Present case) }\end{array}$ & 2014 & 73 & M & Chest pain & ST-T elevation & Anterior to PA & $\begin{array}{l}\text { Significant lesion } \\
\text { in proximal part of } \\
\text { LAD, significant } \\
\text { long lesion in } \\
\text { Diagonal artery } \\
\text { and several } \\
\text { stenosis in OM }\end{array}$ & $\begin{array}{l}\text { CABG for three } \\
\text { vessel disease }\end{array}$ \\
\hline
\end{tabular}

Abbreviations: CABG, coronary artery bypass graft; CAD, coronary artery disease; ECG, electrocardiogram; F, female; M, Male; LAD, left anterior descending artery; OM, obtuse marginal; PA, pulmonary artery; RCA, right coronary artery; PCI, percutaneous coronary intervention.

case and helped in the discussion part. All authors contributed to the writing of the manuscript. All authors read and approved the final manuscript.

\section{References}

1. Lipton MJ, Barry WH, Obrez I, Silverman JF, Wexler L. Isolated single coronary artery: diagnosis, angiographic classification, and clinical significance. Radiology. 1979;130(1):39-47. doi: 10.1148/130.1.39. [PubMed: 758666].

2. Tokmakoglu H, Bozoglan O, Ozdemir L. Right coronary artery originating from left anterior descending artery: a case report.J Cardiothorac Surg. 2010;5:49. doi: 10.1186/1749-8090-5-49. [PubMed: 20529357].

3. Yurtdas M, Gulen $\mathrm{O}$. Anomalous origin of the right coronary artery from the left anterior descending artery: review of the literature. Cardiol J. 2012;19(2):122-9. [PubMed: 22461044].
4. Desmet W, Vanhaecke J, Vrolix M, Van de Werf F, Piessens J, Willems J, et al. Isolated single coronary artery: a review of 50,000 consecutive coronary angiographies. Eur Heart J. 1992;13(12):1637-40. [PubMed: 1289093].

5. Shabestari AA, Akhlaghpoor S, Tayebivaljozi R, Fattahi Masrour F. Prevalence of Congenital Coronary Artery Anomalies and Variants in 2697 Consecutive Patients Using 64-Detector Row Coronary CTAngiography. Iran J Radiol. 2012;9(3):111-21. doi: 10.5812/iranjradiol.8070. [PubMed: 23329976].

6. Davis JA, Cecchin F, Jones TK, Portman MA. Major coronary artery anomalies in a pediatric population: incidence and clinical importance. J Am Coll Cardiol. 2001;37(2):593-7. [PubMed: 11216984].

7. Zamani J, Mahmmody Y. Anomalous right coronary artery originating from the left main coronary artery. Int Cardivasc Res J. 2009;3(4):217-9.

8. Yamanaka O, Hobbs RE. Coronary artery anomalies in 126,595 patients undergoing coronary arteriography. Cathet Cardiovasc Diagn. 1990;21(1):28-40. [PubMed: 2208265]. 
9. Wilson J, Reda H, Gurley JC. Anomalous right coronary artery originating from the left anterior descending artery: case report and review of the literature. Int J Cardiol. 2009;137(3):195-8. doi: 10.1016/j.ijcard.2009.03.140. [PubMed: 19427707].

10. Hosoglu Y, Orem C, Ekrem Turan O, Ozturk M, Gedikli O, Hosoglu A, et al. Right coronary artery originated from the left anterior descending artery in a patient with congenital pulmonary valvular stenosis. Case Rep Cardiol. 2013;2013:413961. doi: 10.1155/2013/413961. [PubMed: 24826286].

11. Nath A, Kennett JD, Politte LL, Sanfelippo JF, Alpert MA. Anomalous right coronary artery arising from the midportion of the left anterior descending coronary artery-case reports. Angiology. 1987;38(2 Pt 1):142-6. [PubMed: 3826751].

12. Biffani G, Lioy E, Loschiavo P, Parma A. Single coronary artery, anomalous origin of the right coronary artery from the left anterior descending artery. Eur Heart J. 1991;12(12):1326-9. [PubMed: 1778201].

13. Rath $\mathrm{S}$, Battler A. Anomalous origin of the right coronary artery from the left anterior descending coronary artery. Catheteriz Cardiovasc Diagnos. 1998;44(3):328-9.

14. Iyisoy A, Kursaklioglu H, Barcin C, Barindik N, Kose S, Demirtas E. Single coronary artery with anomalous origin of the right coronary artery as a branch from the left anterior descending artery: a very rare coronary anomaly. Heart Vessels. 2002;16(4):161-3. [PubMed: 12224788].

15. Takano M, Seimiya K, Yokoyama S, Okamatsu K, Ishibashi F, Uemura $\mathrm{R}$, et al. Unique single coronary artery with acute myocardial infarction: observation of the culprit lesion by intravascular ultrasound and coronary angioscopy. Jpn Heart J. 2003;44(2):271-6. [PubMed: 12718488].

16. Jammula P, Gupta R, Uretsky BF. Images in cardiology: Anomalous origin of the right coronary artery from the left anterior descending artery. Heart. 2005;91(4):ee30. doi:10.1136/hrt.2004.054957. [PubMed: 15772179].

17. Saravanan P, Mennim P, Hancock JE. Anomalous origin of right coronary artery from the mid left anterior descending coronary artery. Heart. 2006;92(9):1212. doi: 10.1136/hrt.2005.078733. [PubMed: 16908690].

18. Kamran M, Bogal M. Anomalous right coronary artery originating from the left anterior descending artery. $J$ Invasive Cardiol. 2006;18(8):E221-2. [PubMed: 16877791].

19. Erdogan O, Buyuklu M, Aktoz M. Anomalous origin of the right coronary artery from the left anterior descending artery in a patient with single left coronary artery: a rare coronary artery anomaly and review of the literature. Int J Cardiol. 2008;127(2):280-3. doi: 10.1016/j.ijcard.2007.04.121. [PubMed: 17658630].

20. Bayram E, Kocaturk H, Kantarci M, Fil F, Colak MC. Anomalous origin of the right coronary artery arising from the left anterior de- scending artery in a case with single coronary artery anomaly: multidetector computer tomography imaging. Anadolu Kardiyol Derg. 2008;8(5):385-6. [PubMed: 18849235].

21. Hsueh SK, Youssef AA, Fang CY. Percutaneous coronary intervention of a stenotic left anterior descending artery with anomalous origin of right coronary artery. Chang Gung Med J. 2009;32(5):574-8. [PubMed: 19840515].

22. Calabro P, Bianchi R, Palmieri R, Sordelli C, Bigazzi MC, Calabro R. Evidence of right coronary from mid-left anterior descending coronary: a rare case of coronary anomalous origin. Eur Heart J. 2009;30(5):565. doi: 10.1093/eurheartj/ehn414. [PubMed: 18786915].

23. Shashanka Mlskdrvv C. Anomalous right coronary artery arising from left anterior descending artery. J Clin Sci Res. 2012;1(3):144-7.

24. Gulati GS, Naik N, Sharma S, Bisoi AK. Anomalous right coronary artery from the left sinus of valsalva diagnosed by multislice computed tomography. Indian Heart J. 2003;55(6):663-5. [PubMed: 14989524].

25. Tchervenkov CI, Pelletier MP, Shum-Tim D, Beland MJ, Rohlicek C. Primary repair minimizing the use of conduits in neonates and infants with tetralogy or double-outlet right ventricle and anomalous coronary arteries. J Thorac Cardiovasc Surg. 2000;119(2):314-23. doi: 10.1016/S0022-5223(00)70187-5. [PubMed: 10649207].

26. Ajami GH, Amirghofran AA, Borzouee M, Navvabi MA, Amoozgar $\mathrm{H}$ Sarikhani S. Coronary Artery Origin Anomalies with Especial Emphasis on Delayed Diagnosis of Anomalous Origin of the Left Coronary Artery from Pulmonary Artery, A report from South of Iran. Int Cardivasc Res J. 2009;3(1):43-8.

27. Ojaghi Haghighi Z, Poorzand H, Bassiri HA. Presentation of anomalous origin of the left coronary artery from the pulmonary artery with left sided coronary ostium in an adult patient. Iran Cardiovasc Res J. 2009;3:109-15.

28. Jo Y, Uranaka Y, Iwaki H, Matsumoto J, Koura T, Negishi K. Sudden cardiac arrest: associated with anomalous origin of the right coronary artery from the left main coronary artery. Tex Heart Inst J. 2011;38(5):539-43. [PubMed: 22163129].

29. Taylor AJ, Rogan KM, Virmani R. Sudden cardiac death associated with isolated congenital coronary artery anomalies. J Am Coll Cardiol. 1992;20(3):640-7. [PubMed: 1512344].

30. Weigold WG, Abbara S, Achenbach S, Arbab-Zadeh A, Berman D, Carr JJ, et al. Standardized medical terminology for cardiac computed tomography: a report of the Society of Cardiovascular Computed Tomography. J Cardiovasc Comput Tomogr. 2011;5(3):136-44. doi 10.1016/j.jcct.2011.04.004. [PubMed: 21640690].

31. Pursnani A, Jacobs JE, Saremi F, Levisman J, Makaryus AN, Capunay C, et al. Coronary CTA assessment of coronary anomalies. J Cardiovasc Comput Tomogr. 2012;6(1):48-59. doi: 10.1016/j.jcct.2011.06.009. [PubMed: 22264632]. 